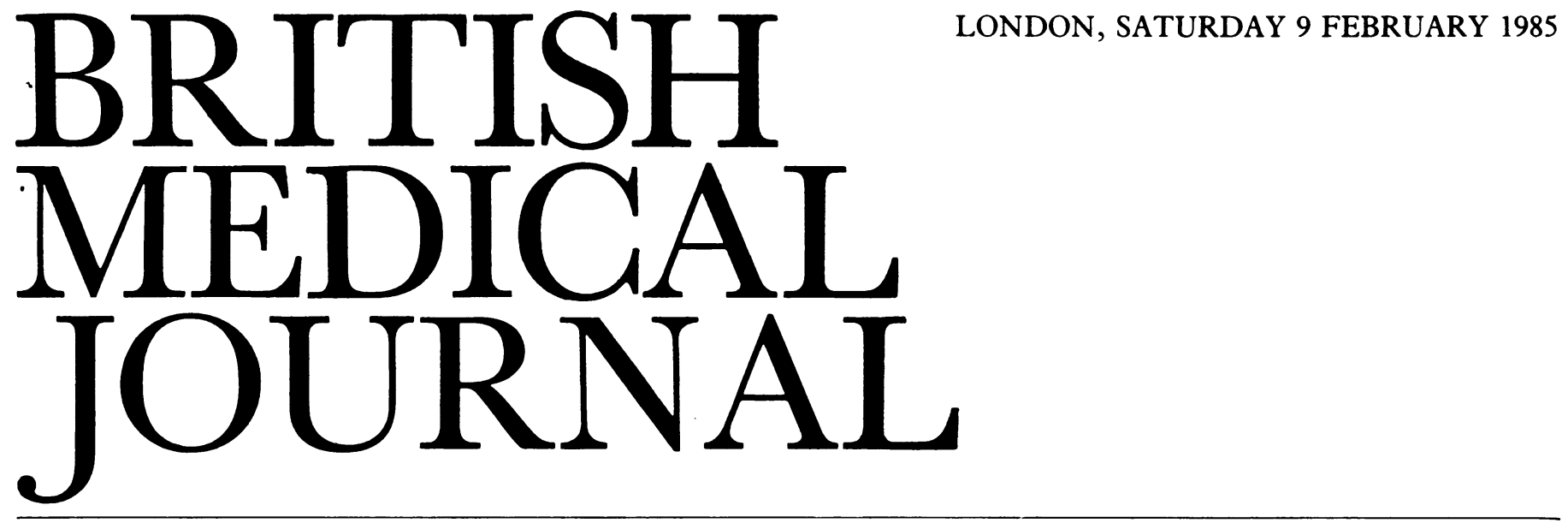

\title{
Chemotherapy for small cell lung cancer
}

Combination chemotherapy has prolonged survival for patients with limited disease small cell lung cancer from a median of three months if untreated to 12 to 16 months and for those with extensive disease from one and a half months to six to 10 months..$^{1-4}$ Nevertheless, early hopes of chemotherapy resulting in a cure rate of $25 \%$ for those with limited disease have not been realised. ${ }^{5}$ Thus it is important to ask how many patients achieve long term survival, how toxic is the treatment, what are the long term side effects, and, finally, should all patients with small cell lung cancer be given chemotherapy?

Data from studies reporting results after two years of follow up after chemotherapy (or chemotherapy and radiotherapy) show that chemotherapy is most effective in patients who present with limited disease. In some series up to half have had a complete response (disappearance of all measurable disease) and nearly a third a partial response (reduction in tumour size of half or more lasting for at least one month). In patients who have presented with widespread disease a quarter have had a complete response and half a partial response. The achievement of a complete response is the main determinant of long term survival. Data from nine studies were recently reviewed and the overall survival rate at two years calculated as $7 \% .^{4}$ This represented $13 \%$ of patients who presented with limited disease (75 of 555) and $2 \%$ of those with extensive disease (18 of 788). The minimum follow up was from 24 to 60 months. The duration of chemotherapy was 18 months (range 4-24), at least 21 patients receiving it for less than six months. Most patients ( 77 of 90 ) received chest irradiation. Of the patients who received additional radiotherapy, $7 \cdot 5 \%$ became long term survivors as against $4 \%$ of those who received chemotherapy alone. Interpretation of the data is not straightforward, however, because only patients with linuted disease were given radiotherapy to the primary turnour site and mediastinum, while all patients with ext. nsive disease received chemotherapy alone.

W'hether or not radiotherapy should be given as well as chernotherapy is not clear. In randomised controlled trials of chemotherapy alone versus chemotherapy and radiotherapy to the primary tumour site and mediastinum irradiation has not improved the median survival in patients with either limited or extensive disease. ${ }^{6-9}$ The number of long term survivors at two or more years has been greater, however, in studies which have included radiotherapy than in those with chemotherapy alone..$^{4-10}$ Nevertheless, a clear cut effect on survival in patients with limited disease who achieve a complete response to chemotherapy has yet to be proved.

Retrospective analyses to identify those patients who are most likely to respond well to treatment have shown that the main prognostic factors are the stage of the disease and the clinical condition of the patient at diagnosis. The size of the tumour at the primary site is also important, smaller tumours responding better and for longer. " Patients who present with extensive disease tend to fare badly, especially those who have cerebral or hepatic metastases. Those with an isolated bone metastasis or single positive result at marrow aspiration may, however, respond as well as patients with limited disease. ${ }^{12}$ Attempts to link prognosis with the results of simple laboratory tests suggest that a high serum albumin concentration is associated with a favourable outcome, ${ }^{13}$ but further studies are required to prove that any single variable influences survival.

Not all patients who survive for two years remain free of tumour. A review of 225 patients treated with chemotherapy and irradiation at the National Cancer Institute showed that 28 patients were free of disease 30 months or more after starting treatment. Thirteen of these subsequently relapsed, eight with small cell lung cancer 31-74 months from diagnosis, three with other malignancies, and two with unknown causes. ${ }^{14}$ A disturbing finding in the 15 survivors who were free of disease was that five had abnormal mental states, four had abnormal computed tomographic brain scans with evidence of cortical atrophy, and seven were unable to resume their occupation. Thus about half of the long term survivors had either some form of disease or limitation of lifestyle related to previous treatment, in addition to running the risk of relapse. ${ }^{14} \mathrm{~A}$ similar review from the MD Anderson Hospital identified 43 patients alive at three years. Eleven of these subsequently relapsed, and death from unrelated causes was documented in another three. ${ }^{15}$ Among the survivors three had severe neurological symptoms including dementia and ataxia, although nine had minor complaints only and 17 remained well. ${ }^{15}$ Whether prophylactic cerebral irradiation-which reduces and delays the incidence of cerebral metastases-is an important determinant of the cerebral deterioration is not known. Undoubtedly the development of the "central nervous system syndrome," with loss of memory, tremor, somnolence, slurred speech, and myoclonus as a possible long term effect of treatment, is a cause for concern, though it has not been reported in all studies of long term survival. ${ }^{16} 17$ The benefits of prophylactic cranial irradiation, 
given as a routine to patients who respond, have not been shown to outweigh the long term disadvantages.

Thus the treatment of patients with small cell lung cancer remains difficult, and in dealing with an aging population (the mean age in most studies has been between 55 and 65) the potential toxicity of treatment must be weighed against the potential for improved survival rates and possible long term survival. There have been few studies assessing quality of life, but in patients who presented with symptoms (as most do) such as anorexia, loss of weight, malaise, haemoptysis, bone pain, or obstruction of the superior vena cava, nearly three quarters had their symptoms relieved by three months, or four courses, of chemotherapy. ${ }^{18}$ The optimal duration of chemotherapy is being investigated. The benefits from treatment seem to occur early and side effects tend to occur later, becoming more noticeable as treatment is prolonged. Data on long term survival suggest that 12 to 18 months' treatment is necessary, but whether this is the optimum duration of treatment is not known, and recent studies of shorter treatment regimens with three and six courses of chemotherapy followed by chest irradiation have shown no difference in median survival. ${ }^{19}$

Current studies should show whether all patients with small cell lung cancer should be treated similarly or whether shorter courses of chemotherapy are more appropriate for giving symptomatic relief in patients with extensive and usually incurable disease. Long term survival occurs in 10$15 \%$ of patients with limited disease, minimal symptoms, small tumour volume, and other favourable prognostic factors. Nevertheless, the optimal duration of chemotherapy, the place of additional radiotherapy, the cause of late neurological sequelae, and the value of further chemotherapy to treat long term survivors who relapse have yet to be defined. Thus further work is needed if we are to improve our management of this aggressive disease.

STEPHEN G SPIRO

Consultant Physician,

Brompton Hospital,

London SW3 6HP

1 Zelen M. Keynote address on biostatistics and data retrieval. Cancer Chemotherapy Reports 1973;4(suppl):31-42.

2 Hande KR, Des Prez RM. Current perspectives in small cell lung cancer. Chest 1984;85:669-77. 3 Greco FA, Einhorn LH, Richardson RL, Oldham RK. Small cell lung cancer: progress and perspectives. Semin Oncol 1978;5:323-35.

4 Morstyn G, Ihde DC, Lichter AS, et al. Small cell lung cancer 1973-1983: early progress and recent obstacles. Int f Radiat Oncol Biol Phys 1984;10:515-39.

5 Oldham RK, Greco FA. Small-cell lung cancer: a curable disease. Cancer Chemother Pharmacol 1980;4:173-7.

6 Hansen HH, Dombernowsky P, Hansen HS, Rorth M. Chemotherapy versus chemotherapy plus radiotherapy in regional small cell carcinoma of the lung-a randomised trial. Proceedings of the American Association for Cancer Research 1979;20:277.

7 Fox RN, Woods RL, Brodie GN, Tattersall MH. A randomised study: small cell anaplastic lung cancer treated by combination chemotherapy and adjuvant radiotherapy. Int $\mathcal{F}$ Radiat Oncol Biol Phys 1980;6:1083-5.

8 Souhami RL, Geddes DM, Spiro SG, et al. Radiotherapy in small cell cancer of the lung treated with combination chemotherapy: a controlled trial. Br Med J 1984;288:1643-6.

9 Stevens E, Einhorn L, Rohn R. Treatment of limited small cell lung cancer. Proceedings of the American Association for Cancer Research 1979;20:435.

10 Bunn PA, Ihde DC. Small cell bronchogenic carcinoma: a review of therapeutic results. In: Livingstone RB, ed. Lung cancer 1. London: Martinus Niihoff, 1981:169-208.

11 Harper PG, Souhami RL, Spiro SG, et al. Tumor size, response rate, and prognosis in small cell carcinoma of the bronchus treated by combination chemotherapy. Cancer Treat Rep 1982;66:463-70.

12 Ihde DC, Makuch RW, Carney DN, et al. Prognostic implications of stage of disease and sites of metastases in patients with small cell carcinoma of the lung treated with intensive combination chemotherapy. Am Rev Respir Dis 1981;123:500-7.

13 Cohen MH, Makuch RW, Johnston-Early A, et al. Laboratory parameters as an alternative to performance status in prognostic stratification of patients with small cell lung cancer. Cancer Treat Rep 1981;65:187-95.

14 Johnson BE, Ihde DC, Lichter AS, et al. Five to 10 year follow up of small cell lung cancer (SCLC) patients disease free at 30 months: chronic toxicities and late relapses. Proceedings of the American Society for Clinical Oncology 1984;25:218.

15 Kalter S, Farha P, Carr DT, Jefrries D, Lee JS, Valdivieso M. Long term survivors with small cell lung cancer (SCLC): the MD Anderson (MDA) experience from 1972-1980. Proceedings of the American Society for Clinical Oncology 1984;25:229.

16 Catane R, Schwade JG, Yarr I, et al. Follow-up neurological evaluation in patients with small cell lung cancer treated with prophylactic cranial irradiation and chemotherapy. Int $\mathcal{Y}$ Radiat Oncol Biol Phys 1981;7:105-9.
17 Livingston RB. Long-term survivors with small-cell lung cancer (SCLC): a South West Oncology Group (SWOG) study. Proceedings of the American Society for Clinical Oncology $\longrightarrow$ 1983;2:187.

18 Geddes DM, Spiro SG, Souhami RL, Harper PG, Tobias JS, Shah S. Symptom response to chemotherapy in small cell lung cancer. Eur $\mathcal{F}$ Respir Dis 1982;63(suppl 125):36.

19 Feld R, Evans WK, DeBoer G, et al. Combined modality induction therapy withour maintenance chemotherapy for small cell carcinoma of the lung. Fournal of Clinical Oncology $1984 ; 2: 294-304$

\section{Platelets and coronary disease, round three}

A fresh thrombus consists of masses of platelets stuck to each ${ }^{\infty}$ other, supported by a mesh of fibrin strands. Arterial $\overrightarrow{0}$ thrombosis usually occurs in association with an atheroma- $\overrightarrow{\vec{\omega}}$ tous plaque, and it seems likely that the development of plaque is the result of repeated thrombotic episodes. ${ }^{1}$ Thus $\frac{0}{3}$ platelets may have an important role in arterial disease and in the sudden clinical events, such as myocardial infarction, $\mathscr{Ð}$ that accompany it. Furthermore, it seems reasonable to expect that patients with arterial disease or thrombosis would have stickier platelets than healthy subjects, and many tests $\oplus$ of platelet function have been devised to test this hypothesis. $\vec{\omega}$

On page $428 \mathrm{Dr} \mathrm{T} W$ Meade and his colleagues describe $\mathrm{O}$ an epidemiological study of what they call platelet aggreg- 0 ability. The technique they used is a modification of Born's $\frac{\Phi}{O}$ optical density method, ${ }^{2}$ which measures changes in the transmission of light through platelet rich plasma as platelets form clumps in response to the addition of aggregating agents $\vec{\bullet}$ such as adenosine diphosphate. In this modified method $10^{\circ}$ concentrations of adenosine diphosphate are tested to estimate the maximum velocity of the change in the transmission? of light (which corresponds to the maximum rate of clump formation) and from this the $\mathrm{ED}_{50}$, or estimated dose of adenosine diphosphate that causes half the maximum $\frac{\AA}{\varnothing}$ response, is calculated.

The platelet aggregability of 958 subjects was studied, of 3 whom 24 had a history of ischaemic heart disease and $54 ?$ evidence of ischaemia in the electrocardiogram. In some? respects aggregability followed the same trends as the risk factors for coronary disease-for example, it increased with age-but in others it did not, being less marked in men; than women and not increased by smoking or by oral contraceptives. The range of $\mathrm{ED}_{50}$ was wide, and, althougho patients with coronary disease had more aggregable platelets than healthy controls, the difference was not significant. This may have been because there were few subjects with coronaryo disease, and it would be helpful to know what would be $\frac{}{2}$ found if the study was repeated on a larger group of patients with age and sex matched control subjects. The observations 0 are, however, consistent with the prevalent view that, thoughw there is a difference in platelet behaviour between groups of healthy subjects and groups of patients with coronary을 disease, it is not possible to show specific platelet abnormalities in individual patients. ${ }^{3}$ This concept represents round three of the platelet and thrombosis story.

Born's original aggregation method was designed to study the formation of clumps of platelets in a test tube. Differences $\frac{\mathbb{Q}}{\mathbb{Q}}$ between groups of patients and healthy subjects were shown, ${ }^{4}{ }^{4}$ but the technique was never found to be useful for identify-o ing individual subjects with vascular disease. In round one of the platelet and vascular disease story, which took place in the early 1960s, many other tests of platelet function were? used and measurements of platelets in whole blood sticking 